\title{
Exploring the regulatory context for HIV self-testing and PrEP market authorisation and use in Nigeria
}

\author{
Osasuyi Dirisu \\ Population Council \\ Oluwafunke llesanmi \\ Akinwumi Akinola \\ Population Council \\ Mayokun Adediran \\ Population Council \\ Waimar Tun \\ Population Council
}

See next page for additional authors

Follow this and additional works at: https://knowledgecommons.popcouncil.org/departments_sbsr-hiv How does access to this work benefit you? Let us know!

\section{Recommended Citation}

Dirisu, Osasuyi, Oluwafunke llesanmi, Akinwumi Akinola, Mayokun Adediran, Waimar Tun, and Rex Mpazanje. 2021. "Exploring the regulatory context for HIV self-testing and PrEP market authorisation and use in Nigeria," Policy Brief. Abuja: Population Council. 


\section{Authors}

Osasuyi Dirisu, Oluwafunke llesanmi, Akinwumi Akinola, Mayokun Adediran, Waimar Tun, and Rex Mpazanje 


\section{EXPLORING THE REGULATORY CONTEXT FOR HIV SELF-TESTING \& PrEP MARKET AUTHORISATION AND USE IN NIGERIA}

\section{INTRODUCTION}

HIV self-testing and pre-exposure prophylaxis are critical entry points for HIV prevention, care, and treatment services

Pre-exposure prophylaxis (PrEP) is an effective HIV prevention strategy among people at high risk of contracting HIV. ${ }^{1}$ Barriers to uptake of PrEP include stigma, challenges attending regular clinic visits, adherence, medication adverse effects, and the fear of being labelled as HIV positive due to the use of antiretrovirals. ${ }^{2}$

HIV self-testing (HIVST) has been shown to overcome many of the barriers to HIV testing, including stigma, poor access to testing health facilities, lack of privacy, and delays in receiving test results. ${ }^{3}$ Research suggests high levels of acceptability and utilisation of oral HIVST in subSaharan Africa, including Nigeria, among subpopulations who may not have easy access to conventional testing services. ${ }^{4,5,6}$

While significant progress has been made in Nigeria with operationalising the implementation of HIVST and PrEP with product approvals and inclusion in national guidelines, there is a need to better understand how the private sector can optimise delivery, including how the market authorisation process and pathways work for HIVST and PrEP service delivery in the private sector.

\section{STUDY AIM}

Funded by the World Health Organization, this study aimed to assess HIVST/PrEP availability and market authorisation; determine the facilitators and barriers to access; and identify existing systems that support the availability, appropriate use, affordability, and accessibility in the private sector in Nigeria.

\section{RECOMMENDATIONS}

- There is urgent need for clarity on the registration process for HIVST and PrEP as well as the role of the National Agency for Food and Drug Administration and Control and Standards Organisation of Nigeria to guide service providers in the procurement process for approved products.

- The implementation of the National Drug Distribution Guidelines should be considered a priority to address inconsistences in the supply chain and availability of HIVST and PrEP.

- The government should provide support to the private sector to develop appropriate operational manuals and referral pathways/ directories at the state level to facilitate linkage to care and follow-up.

- It is necessary to streamline the authorisation process for HIVST/PrEP products in Nigeria to minimise barriers and improve availability and uptake.

\section{METHODS}

In September 2020, we conducted an assessment in four geo-political zones in Nigeria: North Central (Abuja-FCT and Nasarawa), South South (Rivers), South East (Imo), and South West (Lagos and Ogun). Two local government areas in each state, one rural and one urban, were selected. We explored authorisation processes, government policies and support systems affecting availability and use of HIVST and PrEP, as well as supply chain, distribution, pricing by private sector providers, and linkage to post-test services. We conducted a quantitative survey among 151 Patent and Proprietary Medicine Vendors (PPMVs) and 136 Community Pharmacists (CPs) recruited by obtaining the list of providers from the professional association in the states. Stakeholder dialogues (16) and key informant interviews (14) were conducted among government and private sector stakeholders and advocacy groups. Ethical approval was obtained from Population Council's Institutional Review Board.

POPULATION COUNCIL

Ideas. Evidence. Impact. 


\section{KEY FINDINGS}

\section{Registration, authorisation and supply chain for HIVST/PrEP in Nigeria}

About $63 \%$ of CPs and $27 \%$ of PPMVs sold HIVST kits, while $15 \%$ of CPs and no PPMV sold PrEP in their facilities. Most CPs (94\%) and 33\% of PPMVs who sold HIVST kits reported that their facilities were authorised to sell HIVST kits.

- $80 \%$ of HIVST providers and $65 \%$ of PrEP providers checked to see if their products were registered in Nigeria. These providers had varied perceptions of what constitutes appropriate registration.

- Although there is a National Drug Policy that outlines the authorisation, production, and distribution process for medical products and an automated product registration system through the National Agency for Food and Drug Administration and Control, providers reported that the process was cumbersome, time consuming, and expensive.

'You have to pay fees at various levels... You go to somebody's office "come tomorrow, come today". So, something that would have taken you two days, after two months you have not finished, and money is running. At every stage, we have bottlenecks...' CP/PPMV dialogue, Abuja-FCT

The National Drug Distribution Guideline has not been implemented, resulting in a poorly coordinated supply chain for medical products that impacts the supply of quality HIVST and PrEP products in Nigeria.

'...The issue of distribution of drug in Nigeria has been a thorn in the flesh, it has been defective, it has been very chaotic... The national drug distribution guideline... has not come into existence because of the lack of the necessary political will...' CP/PPMV dialogue, Abuja-FCT

\section{Availability of HIVST/PrEP in Nigeria}

A wide range of HIVST brands were sold by providers. The majority of providers procured HIVST and PrEP products from sales representatives and pharmacies, while others procured them from the open market and non-governmental organisations. Reported challenges with the supply of these products include: high costs and lack of funds, distance from suppliers, product scaricity, and variability in demand. There was consensus among stakeholders that lack of awareness about HIVST and PrEP in the community contributes to the suboptimal demand for these services. As shown in Figure 1, there are many HIVST brands sold by providers. Providers, however, need to be guided to correctly identify and procure products that are fully authorised for use in Nigeria.

Suggested citation: Dirisu, Osasuyi, llesanmi, Oluwafunke, Akinwunmi, Akinola, Adediran, Mayokun, Tun, Waimar, \& Mpazanje, Rex. 2021. "Exploring the regulatory context for HIVST \& PrEP market authorisation

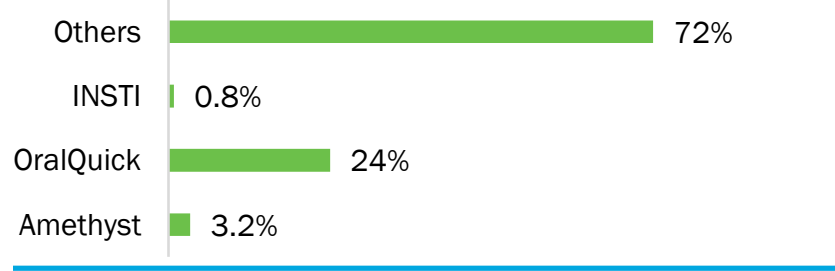

Other brands include Alere Determine, Swe-Care, Dr.Greg, UniGold, $3 \mathrm{H}$ ViralCheck, Tell, Narrowcare, Global, ProMed, and HealthCheck

\section{Appropriate sale of HIVST}

Less than half of PPMVs and CPs (45.6\%) had a standard operating manual for dispensing HIVST, and only about one-third had standard guidelines for HIV testing services. Although $77 \%$ of providers offered counselling prior to sale of HIVST, only $23 \%$ of CPs and $13 \%$ of PPMVs who offered HIVST reported that their facilities were accredited HIV counselling and testing centres. About $85 \%$ of CPs and $43 \%$ of PPMVs reported that they perceive their personnel to be knowledgeable enough to promote or answer questions on HIVST.

\section{Prícing}

HIVST was more expensive at CP than PPMV stores. The mean price of HIVST from CPs were 1138 (\$3.0) while the mean price among PPMV providers was $\$ 548$ (\$1.4). On the other hand, the mean selling price for PrEP was 3947 (\$10.3). There was a consensus among providers that service users considered $\$ 500$ (\$1.3) an appropriate and affordable price for HIVST. Regulatory agencies played a limited role in determining the selling price of HIVST and PrEP as this was considered the prerogative of the manufacturers.

'I think our role is minimal in terms of price regulation... our contribution to the overall price of the drug is minimal, but nevertheless, ... we are trying as much as possible to reduce the cost...' Government stakeholders' dialogue, Lagos

\section{REFERENCES}

1. Mugo, NR, et al. 2016. PrEP for Africa: what we have learnt and what is needed to move to program implementation. Curr Opin HIV AIDS, 11(1), 80-86

2. Emmanuel, G, et al. 2020. Community perspectives on barriers and challenges to HIV PrEP access by men who have sex with men and female sex workers access in Nigeria. BMC Public Health, 20, 69

3. Helleringer, S, et al. Increasing uptake of HIV testing and counseling among the poorest in sub-Saharan countries through home-based service provision. JAIDS 2009;51:185-93

4. Wong, V, et al. 2014. HIV self-testing in resource-limited settings: regulatory and policy considerations. AIDS Behav, 18 Suppl 4: S415-421

5. Tun, W, et al. 2018. Uptake of HIV self-testing and linkage to treatment among men who have sex with men (MSM) in Nigeria: A pilot program using key opinion leaders to reach MSM. J Int AIDS Soc, 21 Suppl 5:e25124

6. Dirisu, 0, et al. 2020. 'I will welcome this one 101\%, I will so embrace it': a qualitative exploration of the feasibility and acceptability of HIV self-testing among men who have sex with men in Lagos, Nigeria. Health Education Research, 35(6), pp.524-537 